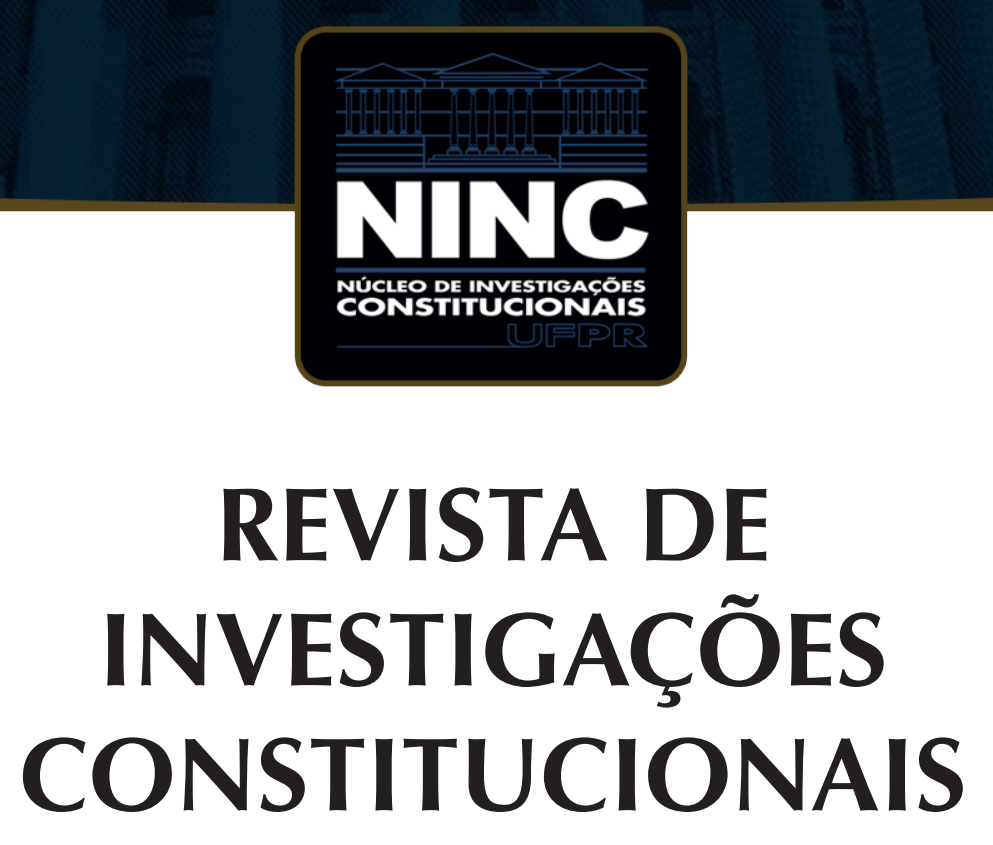

JOURNAL OF CONSTITUTIONAL RESEARCH

vol. 8 | n. 1 | janeiro/abril 2021 | ISSN 2359-5639 | Periodicidade quadrimestral Curitiba | Núcleo de Investigações Constitucionais da UFPR | www.ninc.com.br 


\title{
Direitos humanos, constitucionalismo transnacional e redução das desigualdades raciais: desafios pós-pandemia de Covid-19
}

\section{Human rights, transnational constitutionalism and racial inequality: post-Covid-19 pandemic challenges}

\author{
ANDERSON VICHINKESKI TEIXEIRA I,* \\ ' Universidade do Vale do Rio Sinos (São Leopoldo, Rio Grande do Sul, Brasil) \\ andersonvteixeira@hotmail.com \\ http://orcid.org/0000-0001-7085-0375 \\ FERNANDA FRIZZO BRAGATO 1 , ** \\ ' Universidade do Vale do Rio Sinos (São Leopoldo, Rio Grande do Sul, Brasil) \\ fbragato@unisinos.br \\ http://orcid.org/0000-0002-5398-4643 \\ Recebido/Received: 03.06.2020 / June $3^{\text {rd }}, 2020$ \\ Aprovado/Approved: $25.01 .2020 /$ January $25^{\text {th }}, 2020$
}

\section{Resumo}

Este artigo parte do pressuposto de que o impacto des proporcional da COVID-19 sobre a população negra no Brasil é um problema de racismo estrutural. Por outro lado, assume que o constitucionalismo transnacional surge como alternativa possível para a prevenção de crises globais, como é caso desta pandemia. Nesse sentido, o racismo estrutural, que ressalta o impacto da crise

\section{Abstract}

This article assumes that the disproportionate impact of COVID-19 on the black population in Brazil is a problem of structural racism. On the other hand, it assumes that transnational constitutionalism arises as a possible alternative for the prevention of global crises, such as this pandemic. In this sense, structural racism, which highlights the impact of the global COVID-19 crisis on black people in Brazil, is a

Como citar esse artigo/How to cite this article: TEIXEIRA, Anderson Vichinkeski ; BRAGATO, Fernanda Frizzo. Direitos humanos, constitucionalismo transnacional e redução das desigualdades raciais: desafios pós-pandemia de Covid-19. Revista de Investigações Constitucionais, Curitiba, vol. 8, n. 1, p. 185-207, jan./abr. 2021. DOI: 10.5380/rinc.v8i1.74326.

* Professor do Programa de Pós-Graduação em Direito da Universidade do Vale do Rio dos Sinos (São Leopoldo-RS, Brasil). Doutor em Teoria e História do Direito pela Università degli Studi di Firenze (IT), com estágio de pesquisa doutoral junto à Faculdade de Filosofia da Université Paris Descartes-Sorbonne. Estágio pós-doutoral junto à Università degli Studi di Firenze. Mestre em Direito do Estado pela PUC/RS.. Advogado e consultor jurídico. E-mail : andersonvteixeira@hotmail.com.

** Professora de Direitos Humanos na Graduação e Coordenadora do Programa de Pós-graduação em Direito da Universidade do Vale do Rio dos Sinos (São Leopoldo-RS, Brasil). Pesquisadora Produtividade em Pesquisa CNPq. Graduada em Direito (UFRGS). Mestrado e Doutorado em Direito (UNISINOS). Estágio de pesquisa doutoral no Birkbeck College da Universidade de Londres. Pós-doutorado no Birkbeck College da Universidade de Londres. E-mail : fbragato@unisinos.br. 
global de COVID-19 sobre os negros no Brasil, é um desafio que o constitucionalismo global terá que enfrentar a fim de não reproduzir estruturas implícita ou explicitamente marcadas pelo racismo. Na primeira parte, o artigo recolhe dados preliminares acerca dos impactos da pandemia de COVID-19 no Brasil, sobretudo nos negros. Após, discute estudos atinentes aos temas racismo, poder e discurso. Na terceira parte, reconstrói brevemente conceitos centrais do constitucionalismo transnacional a partir de sua evolução no Ocidente. Por fim, reflete sobre os três possíveis desafios ao constitucionalismo transnacional no combate às desigualdades raciais em cenários pós-pandemia: desafio teórico-normativo, desafio estrutural-funcional e desafio político-pragmático.

Palavras-chave: Direito humanos, constitucionalismo transnacional, racismo, COVID-19. challenge that global constitutionalism will have to face in order to avoid reproducing implicit or explicit structures of racism. In the first part, the article collects preliminary data about the impacts of the COVID-19 pandemic in Brazil, especially among black people. Afterwards, it discusses studies related to the issues of racism, power and discourse. In the third part, it briefly reconstructs central concepts of transnational constitutionalism from its evolution in the West. Finally, it reflects on the three possible challenges to transnational constitutionalism in combating racial inequalities in post-pandemic settings: theoretical-normative challenge, structural-functional challenge and political-pragmatic challenge.

Keywords: human rights; transnational constitutionalism; racism; COVID-19.

\section{SUMÁRIO}

1. Introdução; 2. Acesso desigual à saúde e impactos da pandemia sobre os negros no Brasil; 3. Racismo institucional, poder e discurso; 4. Constitucionalismo transnacional, governança global e a emergência de novas crises; 5. Três desafios ao constitucionalismo transnacional no combate às desigualdades raciais; 6. Conclusões; 7. Referências.

\section{INTRODUÇÃO}

Muito mais do que um problema sanitário, a pandemia de COVID-19 apresenta uma série de dificuldades aos mais diferentes campos do saber. No âmbito jurídico os questionamentos sobre como enfrentar os efeitos durante a pandemia e sobre como projetar as consequências do pós-pandemia, encontram-se no centro das atenções dos juristas de praticamente todas as áreas. No presente artigo, embora os dados quantitativos ainda estejam sendo produzidos, pois esta pesquisa baseia-se em resultados parciais de um fenômeno em curso, o tema central concentra-se na desigualdade racial no Brasil e nos efeitos da pandemia de COVID-19.

Como problema teórico de fundo, pretende-se analisar em que medida os impactos da pandemia podem produzir efeitos de aprofundamento do racismo estrutural característico do Brasil. Se, por um lado, a emergência de uma governança global sanitária e o fortalecimento das estruturas normativas e institucionais do nascente constitucionalismo transnacional surgem como alternativas possíveis para a prevenção de crises globais como a em curso no ano de 2020, verifica-se que, por outro lado, caso não parta de pressupostos teórico-normativos e filosófico-jurídicos que considerem os perigos de uma reprodução funcional de estruturas implícita ou explicitamente marcadas pelo racismo, tais estruturas constitucionais transnacionais e a própria governança global estarão acometidas pela omissão em face de políticas públicas nacionais omissas 
no tratamento das desigualdades raciais, ou até mesmo, acometidas pela consequente assimilação interna de práticas racistas.

Para limitar o alcance do presente estudo, a hipótese que será desenvolvida é no sentido de que, especificamente para o caso do Brasil, a ausência de um constitucionalismo transnacional definidor de noções substanciais antirracistas e de diretrizes de governança global que objetivamente tratem da crise social também levando em consideração o problema do racismo, poderá produzir efeitos de agravamento do racismo estrutural, tendo em vista as perspectivas de uma inédita e longa crise para a economia brasileira nos próximos anos. As matrizes teóricas que fundamentarão essa hipótese são uma combinação entre a perspectiva pós-estruturalista que baseia a noção de racismo estrutural e os estudos pós-coloniais.

Metodologicamente, a pesquisa foi dividida com uma primeira parte meramente analítico-descritiva para, em um recorte temporal que cobre até 31 de maio de 2020, recolher dados preliminares acerca dos impactos da pandemia de COVID-19 no Brasil, sobretudo nos negros. Em um segundo momento, ainda com o mesmo método, estudos atinentes aos temas racismo, poder e discurso serão desenvolvidos para satisfazer o objetivo específico de definir conceitualmente os elementos que serão centrais no restante da pesquisa. Já a terceira parte envolve uma muito breve reconstrução crítico-analítica do constitucionalismo transnacional a partir de sua evolução no Ocidente. Por fim, a parte final da pesquisa suscitará, a partir do método crítico-propositivo que reflexiona a hipótese acima exposta, três possíveis desafios ao constitucionalismo transnacional no combate às desigualdades raciais em cenários pós-pandemia: desafio teórico-normativo, desafio estrutural-funcional e desafio político-pragmático.

\section{ACESSO DESIGUAL À SAÚDE E IMPACTOS DA PANDEMIA SO- BRE OS NEGROS NO BRASIL}

Chamada de COVID-19, doença provocada pelo novo coronavírus (Sars-Cov-2), embora tenha tido seu início na cidade chinesa de Wuhan ${ }^{1}$, rapidamente alcançou todos os continentes do globo terrestre, chegando ao ponto de, em 11 de março de 2020, ser decretada a sua pandemia por parte da Organização Mundial da Saúde (OMS). ${ }^{2}$ De acordo com a OMS, até 31 de maio haviam sido reportados à organização 6.057 .853 casos de COVID-19 confirmados, incluindo 371.166 mortes. $^{3}$

\footnotetext{
WHO. Novel Coronavirus (2019-nCoV). SITUATION REPORT 1. 21 January 2020. Disponível em https:// www.who.int/docs/default-source/coronaviruse/situation-reports/20200121-sitrep-1-2019-ncov.pdf?sfvrs$\mathrm{n}=20$ a99c10_4. Acesso em 18 abr. 2020.

2 WHO. WHO Director-General's opening remarks at the media briefing on COVID-19. 11 March 2020. Disponível em https://www.who.int/dg/speeches/detail/who-director-general-s-opening-remarks-at-the-media-briefing-on-covid-19---11-march-2020. Acesso em 18 abr. 2020.
}

3 WHO. Coronavirus Disease Dashboard. Disponível em https://covid19.who.int. Acesso em 21Abr2020. 
Tratando-se de um vírus altamente transmissível, cujo contágio ocorre principalmente por meio de gotículas que saem de nariz e boca para se dispersarem por até 2 metros, muito rapidamente a COVID-19 tornou-se um grave problema de saúde pública para os países atingidos pelo vírus. Além da alta transmissibilidade, a taxa de mortalidade da doença não obedece a um padrão que ainda tenha sido detectado pelos cientistas e possui, como um dos poucos fatores já claramente detectados, maior letalidade para idosos e pessoas com comorbidades precedentes. ${ }^{4} \mathrm{Um}$ terceiro complicador é o fato de não existir, ainda, remédio eficaz para o tratamento da doença ou vacina para sua prevenção. Como consequência dessa combinação de fatores, a OMS estima que cerca de $40 \%$ das pessoas apresentarão sintomas semelhantes a de uma gripe leve e $40 \%$ dos casos sofrerão sintomas moderados e sem necessidade de internação, embora se inclua nesse percentual os casos de pneumonia em estágio inicial, mas os percentuais restantes é que são o desestabilizador para a médicos, cientistas e sistemas de saúde: $15 \%$ das pessoas desenvolveram sintomas graves, dos quais nem todos ainda previsíveis, e $5 \%$ dos casos serão críticos e com altíssimo potencial de mortalidade. ${ }^{5}$

Com a decretação da pandemia por parte da OMS e com os noticiários internacionais incessantemente cobrindo a rápida difusão de uma doença que pode levar ao colapso dos sistemas de saúde, o Ministério da Saúde brasileiro declarou, em 03 de fevereiro de 2020, a situação de "Emergência em Saúde Pública de Importância Nacional (ESPIN) em decorrência da Infecção Humana pelo novo Coronavírus (2019-nCoV)". ${ }^{6}$ Logo três dias depois a Lei no 13.979 foi promulgada para dispor sobre as "medidas para enfrentamento da emergência de saúde pública de importância internacional decorrente do coronavírus responsável pelo surto de 2019."7 Todavia, o momento mais importante do ponto de vista jurídico-normativo, mas não menos importante também do ponto de vista simbólico, tendo em vista que contou com a assinatura até mesmo do Presidente do Supremo Tribunal Federal, Min. Dias Toffoli, ocorreu em 20 de março de 2020 com a decretação do "estado de transmissão comunitária do coronavírus em todo território nacional". 8 Ainda que se trate de uma lei com fins fiscais no sentido de otimizar a gestão de recursos para o combate à pandemia, a referida data é importante

\footnotetext{
4 Ver: WAYNE, C. K.; WILLIAMS, Michelle. Covid-19 and Immunity in Aging Populations - A New Research Agenda. The New England Journal of Medicine, [s.l.], vol. 383, n. 9, p. 804-805, abr. 2020. Ver também: WHO. COVID-19 STRATEGY UPDATE. 14 April 2020. Disponível em https://www.who.int/emergencies/diseases/novel-coronavirus-2019/strategies-plans-and-operations. Acesso em 18 de abril de 2020.

5 WHO. COVID-19 STRATEGY UPDATE. 14 April 2020. Disponível em https://www.who.int/emergencies/ diseases/novel-coronavirus-2019/strategies-plans-and-operations. Acesso em 18 de abril de 2020.

6 BRASIL. PORTARIA N. 188, de 03/02/2020. Disponível http://www.in.gov.br/web/dou/-/portaria-n-188-de-3-de-fevereiro-de-2020-241408388. Acesso em 18 abr. 2020.

7 Disponível em http://www.planalto.gov.br/ccivil_03/_ato2019-2022/2020/lei/L13979.htm. Acesso em 18 abr. 2020.

8 BRASIL. PORTARIA N. 454, de 20/03/ 2020. Disponível em http://www.in.gov.br/en/web/dou/-/portaria-n-454-de-20-de-marco-de- 2020-249091587. Acesso em 18 abr. 2020.
} 
porque a partir dela Estados e Municípios iniciaram medidas restritivas e de quarentena para controle da pandemia.

Diante da inexistência de vacina para a prevenção ou de medicamento comprovadamente eficaz, a OMS preconiza uma série de medidas para a contenção da pandemia, ressaltando que todas dependem do contexto de cada país e de suas capacidades de envolver em processos colaborativos indivíduos, comunidades, governos locais e empresas privadas. Destaca que "a resposta global mais importante ao COVID-19 até o momento talvez tenha sido diagnosticar com precisão, isolar e cuidar com eficácia de todos os casos da doença, incluindo os leves ou moderados, com o objetivo de reduzir a velocidade da transmissão e proteger os sistemas de saúde com sucesso." ${ }^{\prime 9}$

No entanto, não sendo possível o diagnóstico e prevenção por meio de testagem das populações, a OMS reconhece que "medidas de distanciamento físico e restrições de movimento, geralmente chamadas de shut downs e lock downs, podem retardar a transmissão do COVID-19, limitando o contato entre as pessoas". A própria OMS adverte que "essas medidas podem ter um impacto negativo profundo", e que "afetam desproporcionalmente grupos desfavorecidos, incluindo pessoas em situação de pobreza, migrantes, deslocados internos e refugiados, que costumam viver em locais superlotados e com poucos recursos, e dependem do trabalho diário para subsistência." Mesmo assim, "o levantamento prematuro das medidas de distanciamento físico provavelmente levará a um ressurgimento descontrolado da transmissão do COVID-19 e a uma segunda onda ampliada de casos", caso os Estados não adotem "um planejamento cuidadoso e na ausência de capacidades ampliadas de saúde pública e de atendimento clínico". ${ }^{10}$

Por consequência, é facilmente verificável que enfrentamento da COVID-19 e a contenção da disseminação do vírus depende de ações coordenadas, bem planejadas e abrangentes dos governos em seus mais diferentes níveis. Assim, as populações dos Estados com insuficiente governança e acometidas por débeis estruturas de efetivação de políticas públicas serão as mais afetadas. No Brasil, os primeiros dados mostram, como veremos a seguir, que as iniquidades já existentes no acesso ao sistema de saúde por parte de pessoas negras só se aprofundaram durante a pandemia em curso. De um modo geral, as condições preexistentes de desigualdade no acesso a direitos, especialmente por meio de políticas públicas, mostram-se como fatores de agravamento da vulnerabilidade da população negra frente à pandemia.

9 WHO. COVID-19 STRATEGY UPDATE. 14 April 2020. Disponível em https://www.who.int/emergencies/ diseases/novel-coronavirus-2019/strategies-plans-and-operations. Acesso em 18 abr.2020.

10 "Therefore, as we have always said, lock-downs in their own right are not a solution but those population-wide physical distancing measures have proved quite effective in countries where there's been a rapid escalation of cases, sometimes as a result of not being successful in containing the disease in the first place. Those measures have served to suppress some of the transmission." WHO. COVID-19 virtual press conference. 15 April 2020. Disponível em https://www.who.int/docs/default-source/coronaviruse/transcripts/who-audio-emergencies-coronavirus-press-conference-15apr2020.pdf?sfvrsn=1b9ed28d_2 Acesso em 18 abr. 2020. 
Partindo dos dados oficiais do Ministério da Saúde, do Boletim Epidemiológico Especial relativo à semana de 17 a 23 de maio, ao observar as hospitalizações por Síndrome Respiratória Aguda (SRAG) decorrentes de coronavírus, verifica-se que: 49,0\% das hospitalizações eram de pessoas de raça/cor branca, 42\% parda, 7,1\% preta. De um total de 168.676, foram excluídas da análise 19.266 internações que não tiveram identificação neste critério. Quando se observa os números de óbitos, o percentual de brancos cai para $41 \%$, o de pardos sobe para $49,6 \%$ e o de pretos para 7,4 . O Boletim tomado aqui é o número 17, mas ele apenas demonstra a mesma tendência de menor número de óbitos entre brancos na proporção com hospitalizados do que em relação os demais grupos catalogados. ${ }^{11}$

Acrescente-se ainda o fato notório e amplamente divulgado na imprensa de que o Ministério da Saúde só começou a incluir o critério "raça/cor" no Boletim Epidemiológico em 10 de abril, a partir de pedido feito por parte da Sociedade Brasileira de Medicina da Família e Comunidade (SBMFC). Já em 05 de maio a Justiça Federal do Rio de Janeiro determinou a inclusão de dados sobre a etnorraça a partir de ação judicial impetrada pela Defensoria Pública da União e pelo Instituto Luiz Gama. ${ }^{12}$

Importante ressaltar que a subnotificação compromete muito a factibilidade dos dados acima trazidos, pois o próprio Ministério da Saúde informa que, para cada um milhão de habitantes, são realizados 4.378 testes, o que representa um total de 930.013 testes realizados até 31 de maio de 2020. ${ }^{13}$ Na comparação com os países com maior número de infectados, considerando os dados desta mesma data, torna-se flagrante a baixíssima testagem ocorrida no Brasil até então:

\begin{tabular}{|c|c|c|c|}
\hline País & Total de casos & Total de óbitos & Total de testes realizados \\
\hline EUA & 1.873 .170 & 106.195 & 17.672 .567 \\
\hline Brasil & 514.992 & 29.341 & 930.013 \\
\hline Rússia & 405.843 & 4.693 & 10.643 .124 \\
\hline Espanha & 286.509 & 27.127 & 4.063 .843 \\
\hline Reino Unido & 274.762 & 38.489 & 4.285 .738 \\
\hline
\end{tabular}

Fonte: Worldometer Coronavirus - www.worldometers.info/coronavirus

11 BRASIL. Ministério da Saúde. Boletim Epidemiológico Especial, número 17. SE 21, 23 de maio de 2020.

12 BRASIL. Ministério da Saúde. Painel Coronavírus, 31 de maio de 2020. https://covid.saude.gov.br

13 BRASIL. Ministério da Saúde. Boletim Epidemiológico Especial, número 15. SE 19, 08 de maio de 2020. 
Se somente esses dados estatísticos já seriam preocupantes, há ainda alguns fatores que podem levar a um quadro de maior vulnerabilidade da população negra brasileira em face da pandemia de COVID-19. Pesquisa recentemente publicada pelo Centro Brasileiro de Estudos de Saúde, intitulada "Covid-19 e desigualdade no Brasil" leva em consideração a questão econômica, isto é, a renda, para tratar do tema em questão. ${ }^{14}$ Todavia, deve-se partir do pressuposto de que os dados do IBGE (Instituto Brasileiro de Geografia e Estatística) relativos ao ano de 2018, indicam que, mesmo constituindo $55,8 \%$ da população brasileira, o total de pretos ou pardos que estão vivendo em extrema pobreza chega a $75 \%$ dos indivíduos. Segundo o estudo acima referido, o maior percentual de negros nas faixas economicamente mais frágeis concentra uma série de fatores que são altamente favoráveis à propagação do vírus: maior necessidade de uso de transporte público, maior exposição à informalidade no mercado de trabalho - logo, menor probabilidade de conseguir trabalhar remotamente -, maior concentração de pessoas vivendo em um mesmo domicílio, precariedade no acesso a serviços essenciais, como saneamento básico e, por fim, uma grande dependência do Sistema Único de Saúde. Especificamente em relação a negros, quase $80 \%$ dos que dependem do SUS são autodeclarados negros. ${ }^{15} \mathrm{~A}$ conclusão das três autoras do citado estudo foi no sentido do defendido pela Organização Mundial da Saúde e por diversas entidades de classe na área da saúde: necessidade de ampliação do número de leitos disponíveis no SUS e a combinação de isolamento social com políticas de preservação da renda.

No que concerne ao SUS, há um elemento importante a considerar para fins de transição ao item seguinte da presente pesquisa: o racismo institucional. Diversos estudos nas mais variadas áreas analisam as dificuldades de negros no acesso à saúde pública no Brasil. Kalckmann, Santos, Batista e Cruz realizaram uma pesquisa que contou com questionário autoaplicável sobre a percepção do entrevistado acerca do racismo e relato de experiências vivenciadas. Dos 240 questionários respondidos por lideranças do movimento negro, gestores e profissionais da saúde que atuam no SUS, 43,3\% disseram já ter percebido algum tipo de discriminação racial nos serviços de saúde pública. O percentual na amostra em tela é reconhecido como alto pelos próprios autores da pesquisa, quando em comparação com outros estudos. ${ }^{16}$ No entanto, o dado já se mostra suficiente para refletir uma percepção presente no senso comum e na própria

\footnotetext{
14 PIRES, Luiza Nassif; XAVIER, Laura de Lima; CARVALHO, Laura. Coronavírus e desigualdade no Brasil. CEBES, 06 de abril de 2020. http://cebes.org.br/2020/04/covid-19-e-desigualdade-no-brasil/

15 NAÇÕES UNIDAS BRASIL. Quase $\mathbf{8 0} \%$ da população brasileira que se autodeclara negra depende do SUS. 05 de dezembro de 2017. https://nacoesunidas.org/quase-80-da-populacao-brasileira-que-depende-do-sus-se-autodeclara-negra/

16 KALCKMANN, Suzana; SANTOS, Claudete Gomes dos; BATISTA, Luís Eduardo; CRUZ, Vanessa Martins da. Racismo institucional: desafio para a equidade no SUS? Saúde e Sociedade, [s.l.], vol. 16, n. 2, p. 146-155, 2007, p. 151.
} 
linguagem popular do brasileiro: pessoas negras são "mais fortes e resistentes à dor." Alguns dos relatos indicaram não ser raro ouvir que: "'Negro não adoece' (51 anos, auxiliar de enfermagem, preta); (...) 'Eu estava com muita dor e a médica falava: que é isso? Não dói tanto' (23 anos, professora, parda); 'Rapaz! Um negão desse tamanho sentindo dor?' (55 anos, agente comunitário de saúde, cor preta). ${ }^{17}$

A mesma pesquisa indicou ainda que pretos e pardos tendem a ter uma pior assistência ao parto e um pré-natal muito mais limitado em termos de acompanhamentos, o que gera dúvidas, por exemplo, quanto à relação possível entre a predominância de anemia falciforme (doença hereditária mais comum no Brasil) e precário acesso à saúde. ${ }^{18}$ Já o estudo de Jurema Werneck indica que os dados epidemiológicos existentes são suficientes para demonstrar como o critério raça/cor, independentemente de sua composição com outros critérios, é ilustrativo do profundo impacto que o racismo produz nas condições de saúde, na carga de doenças e, por fim, nas taxas de mortalidades da população negra. ${ }^{19}$

\section{RACISMO INSTITUCIONAL, PODER E DISCURSO}

O acesso desigual ao sistema de saúde e o atual impacto adverso da pandemia de COVID-19 sobre os negros convergem em muitos aspectos com aquilo que muitos autores vêm chamando de racismo institucional e cuja ocorrência no país tem sido reconhecida por organismos internacionais.

Ao julgar o caso Simone André Diniz contra o Brasil, em 2006, a Comissão Interarmericana de Direitos Humanos, reconheceu a existência de racismo institucional no sistema de justiça brasileiro. O órgão internacional asseverou ter "conhecimento que o racismo institucional é um obstáculo à aplicabilidade da lei antiracismo no Brasil". Reconheceu que esta "prática tem como efeito a discriminação indireta na medida em que impede o reconhecimento do direito de um cidadão negro de não ser discriminado e o gozo e o exercício do direito desse mesmo cidadão de aceder à justiça para ver reparada a violação." Por fim, pontuou a diferença existente entre o racismo consciente e explícito do racismo institucional. O primeiro se manifestaria na forma de insultos raciais, que, mesmo sendo repreensíveis, são menos importantes para a manutenção

\footnotetext{
17 KALCKMANN, Suzana; SANTOS, Claudete Gomes dos; BATISTA, Luís Eduardo; CRUZ, Vanessa Martins da. Racismo institucional: desafio para a equidade no SUS? Saúde e Sociedade, [s.l.], vol. 16, n. 2, p. 146-155, 2007, p. 151.

18 KALCKMANN, Suzana; SANTOS, Claudete Gomes dos; BATISTA, Luís Eduardo; CRUZ, Vanessa Martins da. Racismo institucional: desafio para a equidade no SUS? Saúde e Sociedade, [s.l.], vol. 16, n. 2, p. 146-155, 2007, p. 152.

19 WERNECK, Jurema. Racismo institucional e saúde da população negra. Saúde e Sociedade, [s.I.], vol. 25, n. 3, p. 535-549, 2016, p. 541.
} 
da desigualdade racial do que as sutis práticas individuais e institucionais derivadas de uma forma de pensar que naturaliza a hierarquia racial, estas sim, de natureza "institucional". ${ }^{20}$

Posteriormente, foi a vez de um organismo da Organização das Nações Unidas chegar a conclusão semelhante. Em sua visita ao Brasil, em 2013, o Grupo de Trabalho sobre pessoas afrodescendentes concluiu, em seu relatório final, que, embora exista um elevado percentual de afro-brasileiros na população e sejam claros os esforços e avanços no combate à discriminação, existe um racismo institucional e estrutural que não poderá ser enfrentado somente com os mecanismos jurídicos e legislações existentes. ${ }^{21}$

No entanto, a cunhagem do termo racismo institucional é atribuído a Stokely Carmichael e Charles Hamilton, ativistas da década de 1960, que definiram o fenômeno a partir da implementação de decisões e políticas baseadas no critério raça para fins de subordinar um grupo racial e manter o controle sobre esse grupo. ${ }^{22}$ Seria uma transição de processos subjetivos, meramente individuais, para processos coletivos e com sua afirmação por meio das instituições, sejam elas públicas ou privadas.

Camara P. Jones (2002) entende o racismo como um sistema composto por três dimensões: racismo pessoal-mediado (personally-mediated), racismo internalizado (internalized) e racismo institucional (institutionalized). A autora define o primeiro como uma forma de racismo ainda essencialmente pessoal, baseado na discriminação intencional ou involuntária. Já o internalizado se manifestaria por meio da aceitação por parte dos membros estigmatizados em relação às mensagens negativas sobre suas habilidades e valor intrínseco. Diferentemente, o racismo institucional é definido por meio de estruturas, políticas, práticas e normas que resultam em acessos desiguais a bens, serviços e oportunidades na sociedade tão somente com base no critério "raça". ${ }^{23} \mathrm{Em}$ sua dimensão institucional o caráter sistêmico do racismo torna irrelevante a discussão sobre intencionalidade, pois a estrutura institucional assegura a exclusão seletiva dos grupos racialmente subordinados.

Uma outra perspectiva conceitual possível é a de Silvio Almeida, que distingue o racismo em três concepções: individualista, institucional e estrutural. Ressaltando que os dois últimos não são sinônimos, inicia pela concepção individualista, pois o racismo

\footnotetext{
20 CIDH. COMISSÃO INTERAMERICANA DE DIREITOS HUMANOS. Relatório n. 66/06. Caso 12.001 MÉRITO. SIMONE ANDRÉ DINIZ BRASIL, 21 de outubro de 2006.

21 "Despite the high percentage of Afro-Brazilians in the population and the serious efforts and advances that have been made in combating direct discrimination against people of African descent, the Working Group is concerned by the ongoing structural and institutional racial discrimination and xenophobia that cannot be effectively addressed with the existing legal mechanisms and legislation." UNITED NATIONS. Human Rights Council. Report of the Working Group of Experts on People of African Descent on its fourteenth session. Mission to Brazil. A/HRC/27/68/Add.1. 4 September 2014.

22 ALMEIDA, Silvio. Racismo estrutural. São Paulo: Pólen, 2019, p. 21.

23 JONES, Camara P. Confronting Institutionalized Racism. Phylon, [s.l.], vol. 50, n. 1/2, p. 7-22, 2002, p. 10-11.
} 
iniciaria, antes de tudo, como uma espécie de patologia social que acomete o indivíduo por se tratar de um "fenômeno ético ou psicológico de caráter individual ou coletivo, atribuído a grupos isolados; ou, ainda, a uma 'irracionalidade' a ser combatida no campo jurídico por meio de aplicação de sanções civis - indenizações, por exemplo - ou penais". 24 Por consequência, quando não externada de modo direto a alguém, tal forma de racismo não passaria de mero preconceito.

O racismo institucional seria o resultado de uma dinâmica de funcionamento das instituições que passam a conferir, direta ou indiretamente, desvantagens e privilégios com base na raça. Assim, o grupo dominante depende da sua capacidade de institucionalizar seus interesses e impor suas regras e padrões de condutas como algo normal ao sistema. Tais regras e padrões comportamentais dificultariam a ascensão de negros e mulheres aos principais postos de liderança, tornando o estereótipo do homem branco o padrão dominante institucional. ${ }^{25}$

O mesmo Almeida explica que, por outro lado, o racismo estrutural envolve o tecido social de modo mais abrangente. Se há um racismo institucional mediante a imposição de regras e padrões racistas por parte das instituições tomadas individualmente, significa falar que há também um modo de socialização que tem o racismo como um de seus componentes orgânicos. O fato de estar presente no cotidiano, de modo naturalizado, demonstraria que as instituições só são racistas porque a sociedade é estruturalmente racista na formação de suas relações sociais, econômicas e políticas. Segundo o mesmo autor, é o que geralmente "acontece nos governos, empresas e escolas em que não há espaços ou mecanismos institucionais para tratar de conflitos raciais e sexuais." 26

No que tange ao vínculo conceitual do racismo com a teoria da raça, Francisco Bethencourt propõe superar a ideia de que "a teoria das raças antecede o racismo", pois esta seria uma visão que colocaria tal teoria na condição de instrumento justificador da discriminação e da segregação; ele destaca inclusive que a responsabilidade por conflitos étnicos anteriores é própria dos "antagonismos religiosos".27 No mesmo sentido, Tzvetan Todorov salienta que racismo e racialismo são fenômenos distintos. Racismo, em sua acepção comum, designa o comportamento do racista, na maior parte das vezes caracterizado por ódio e menosprezo em relação a pessoas que possuem certas características físicas bem definidas. Já racialismo é a nomenclatura que se reserva para as doutrinas constituídas a partir de argumentos e justificações científicas. A doutrina racialista pode ser apresentada como um conjunto coerente de cinco proposições: (1)

24 ALMEIDA, Silvio. Racismo estrutural. São Paulo: Pólen, 2019, p. 28.

25 ALMEIDA, Silvio. Racismo estrutural. São Paulo: Pólen, 2019, p. 21.

26 ALMEIDA, Silvio. Racismo estrutural. São Paulo: Pólen, 2019, p. 22.

27 BETHENCOURT, Francisco. Racismo: das Cruzadas ao século XX. São Paulo: Companhia das Letras, 2018, p. 24. 
a existência das raças; (2) a continuidade entre o físico e o moral; (3) a ação do grupo sobre o indivíduo; (4) hierarquia única de valores; e (5) política fundada no saber. A biologia contemporânea não reconhece a noção de raça para estudar as variações físicas entre os seres humanos, dada a existência de uma raça única, a humana. Mesmo assim, a doutrina racialista que parte do argumento da existência de raças distintas entre os seres humanos considera as diferenças físicas como marcadores da existência de raças distintas em termos biológicos. ${ }^{28}$

Para efeito de transição argumentativa, é importante destacar que o conceito de racismo, quando tomado em seu sentido estrutural, baseia-se em uma perspectiva relacional. Isto é, a raça não é uma figura linguística, nem um mero dado biológico: trata-se de uma noção que se manifesta em uma estrutura social marcada por conflitos e antagonismos que colocam em evidência a possibilidade de exercício concreto de poder por parte dos indivíduos e grupos nas suas mais diferentes relações. ${ }^{29}$ Refletindo no campo propriamente filosófico, seria então o racismo estrutural um fenômeno melhor observado sob a perspectiva do estruturalismo ou do pós-estruturalismo?

Tanto o estruturalismo quanto o pós-estruturalismo podem auxiliar a compreender o racismo em termos gerais não como uma prática limitada a manifestações individuais e conscientes, pois a própria não intencionalidade seria um elemento configurador do racismo em sua variante estrutural. No entanto, importante recordar que o estruturalismo começou a se desenvolver como "uma forma de poética, de crítica literária e de análise linguística do discurso, substituindo, dessa forma, o modelo humanista que interpretava textos particulares como sendo a expressão singular de um determinado autor." ${ }^{\prime 30}$ Os trabalhos iniciados por Saussure ${ }^{31}$ e Roman Jakobson ${ }^{32}$ apontavam para a correta compreensão das relações sociais e, de um modo geral, de todos os fenômenos das relações humanas a partir de modelos linguísticos que estivessem em condição de expor, descrever, narrar, as relações de equivalência e oposição que estão presentes nas relações sociais. Em poucas palavras, o estruturalismo buscava dar forma linguística a um humanismo que, sem a mediação da linguagem, não encontraria meios de se expressar.

Com o estruturalismo de Claude Lévi-Strauss vimos uma aproximação filosófica entre a linguística de Saussure e a psicanálise de Freud ao fundar um método estruturalista que seria de grande impacto na antropologia social. Analiticamente, Lévi-Strauss

\footnotetext{
28 TORODOV, Tzvetan. Nosotros y los otros: reflexión sobre la diversidad humana. Madrid: Siglo XXI, 2007, p. 116-117.

29 ALMEIDA, Silvio. Racismo estrutural. São Paulo: Pólen, 2019, p. 24.

30 PETERS, Michael. Pós-estruturalismo e filosofia da diferença. Belo Horizonte: Autêntica, 2000, p. 15.

31 Ver, por todos, SAUSSURE, Ferdinand de. Cours de linguistique générale. 3 ed. (1 ed. de 1916) Paris: Payot, 1931.

32 Ver, por todos, JAKOBSON, Roman. Essais de linguistique générale. Tomos I e II. Paris: Les Éditions de Minuit, $1963 ; 1973$.
} 
dizia que raça, ou qualquer outro termo que venha a substituí-lo com mesmo sentido, "designará, então, uma população ou um conjunto de populações que diferem das outras pela maior ou menor grande frequência de certos genes." ${ }^{133}$ Por consequência, qualquer pesquisa sobre as origens das diferenças raciais comprovaria que o debate intercultural não se dá sobre a diversidade de raças, mas sim sobre a diversidade de culturas, caso contrário, o debate se restringiria somente à pesquisa biológica. ${ }^{34}$ Lévi-Strauss afirmava que a "necessidade de preservar a diversidade das culturas em um mundo ameaçado pela monotonia e pela uniformidade certamente não escapa às instituições internacionais. Elas entendem também que não será suficiente, para atingir este fim, agradar tradições locais e convencionar uma pausa aos tempos passados." ${ }^{35}$ Embora tenha sido com Antropologia estrutural (1958) que Lévi-Strauss esquematizou os fundamentos de seu método estrutural, foi a obra Tristes trópicos (1955) que o tornou célebre ao narrar suas experiências com pesquisas etnográficas sobretudo no Brasil, mas também em países da Ásia e Oriente Médio. ${ }^{36}$

Jean Piaget, psicólogo contemporâneo de Lévi-Strauss, entendia a estrutura como um sistema de transformações. Não seria uma estrutura meramente composta por elementos e suas propriedades, mas seria essencialmente composta por transformações nesses elementos que envolvem suas próprias leis de transformação, as quais nunca conduzem a resultados externos ao sistema, nem empregam elementos identificantes que sejam externos ao próprio sistema. Piaget resume seu conceito de estrutura na composição dinâmica de três características essenciais: totalidade, transformação e autorregulação. ${ }^{37}$

Resumidamente, a ideia de totalidade significaria compreender a estrutura como sistema composto por elementos definidos e orientados por leis em comum. Já a ideia de transformação remete ao fato de que a estrutura não é um sistema estático, mas sim dinâmico e com relações de interação que constantemente colocam em discussão os elementos definidos a partir de interações com outros elementos internamente presentes. Quanto à autorregulação, permite que o sistema se estruture

33 No original: "désignerait alors une population ou un ensemble de populations qui diffèrent d'autres par la plus ou moins grande fréquence de certains gènes." LÉVI-STRAUSS, Claude. Race et Histoire; Race et Culture. Paris: Albin Michel et UNESCO, 2001, p. 124.

34 "Si donc on essaye de faire remonter les différences raciales aux origines, on s'interdit pas là même d'en rien savoir, et ce dont on débat en fait n'est pas la diversité de races, mais la diversité de cultures." LÉVI-STRAUSS, Claude. Race et Histoire; Race et Culture. Paris: Albin Michel et UNESCO, 2001, p. 125.

35 No original: "nécessité de préserver la diversité des cultures dans un monde menacé par la monotonie et I'uniformité n'a certes pas échappé aux institutions internationales. Elles comprennent aussi qu'il ne suffira pas, pour atteindre ce but, de choyer des traditions locales et d'accorder un répit aux temps révolus." LÉVI-STRAUSS, Claude. Race et Histoire; Race et Culture. Paris: Albin Michel et UNESCO, 2001, pp. 119-120.

36 Ver LÉVI-STRAUSS, Claude. Anthropologie structurale. Paris: Plon, 1958; e LÉVI-STRAUSS, Claude. Tristes tropiques. Paris: Plon, 1958.

37 PIAGET, Jean de. Le structuralisme. Paris: PUF, 1968, p. 6-8. 
de modo a receber também manifestações íntimas dos elementos em interação; seria dessa capacidade de autorregulação que a estrutura retiraria a sua potencialidade de reconhecimento por parte dos elementos presentes no sistema.

Essa perspectiva estruturalista parece figurar como substrato teórico de pesquisas referidas aqui da área da saúde pública e também pesquisas do meio jurídico, como a de Silvio Almeida. Todavia, ocorre que para Michel Foucault as investigações estruturalistas seriam concentradas no primado do sujeito e, por consequência, da sua racionalidade. O pós-estruturalismo foucaultiano é muito ilustrativo da vinculação dessa perspectiva com o próprio pós-modernismo, de modo que a superação das estruturas - não sua eliminação - é o ponto central da discussão. O estruturalismo seria maculado pela dissolução do que Foucault chama de "acontecimento" em meio a uma tradição da história, teleológica ou racionalista, que sustenta haver uma continuidade ideal, natural, no evoluir do ser. O acontecimento seria a dimensão do irracional, do impensável, daquilo que não entra, nem pode entrar, na pretensa totalidade da estrutura quando pensada à luz do estruturalismo. ${ }^{38}$ Mais ainda: a noção de poder seria deslocada das instituições para as relações em concreto dos indivíduos. No pós-estruturalismo foucaultiano o poder se exerceria em relações, antes de em instituições ou estruturas.

Nos diversos momentos em que aborda o conceito de poder, desde a História da sexualidade até suas lições no Collège de France, torna-se flagrante o caráter pós-moderno que notabilizou o referido autor. Na Conclusão de $A$ arqueologia do saber Foucault inicia o primeiro parágrafo falando que ao longo do livro o leitor teria tentado se "destacar do estruturalismo", ou de qualquer coisa que a palavra possa indicar. ${ }^{39} \mathrm{O}$ pós-estruturalismo seria, assim, uma compreensão da história das ideais a partir de relações sociais em concreto e marcadas pela instabilidade e volatilidade da pós-modernidade.

O racismo estrutural seria, então, filosoficamente estruturalista ou pós-estruturalista? Sem a mínima pretensão de respostas definitivas, aderimos à perspectiva pós-estruturalista pela própria natureza do fenômeno político no século XXI e do modo como o fenômeno jurídico irá enfrentar, quando em escala transnacional, as disfuncionalidades sistêmicas e a emergências de novas formas de regulação jurídica. A dimensão do racional, tão fortemente presente no estruturalismo, divide espaço com o instintivo, involuntário, irracional, que permeia as relações sociais de modo geral na pós-modernidade. Portanto, ao pensarmos o papel do constitucionalismo transnacional no combate às desigualdades sociais e, em especial, às desigualdades raciais, esse pressuposto filosófico será de singular valia para a fundamentação epistemológica dos dois próximos itens desta pesquisa.

38 FOUCAULT, Michel. Microfísica do poder. 4 ed. Rio de Janeiro: Graal, 1984, p. 5-7.

39 "Tout au long de ce livre, vous avez essayé, tant bien que mal, de vous démarquer du 'structuralisme' ou de ce qu'on entend d'ordinaire par ce mot." FOUCAULT, Michel. L’archéologie du savoir. Paris: Gallimard, 1969, p. 269. 


\section{CONSTITUCIONALISMO TRANSNACIONAL, GOVERNANÇA GLOBAL E A EMERGÊNCIA DE NOVAS CRISES}

Inicialmente, um questionamento poderia ser feito: qual a relação entre o constitucionalismo transnacional - fenômeno cujos principais desenvolvimentos teóricos iniciaram-se no pós-Segunda Guerra Mundial e que encontram no século XXI aquela que parece ser sua era típica - e o combate à desigualdade racial?

Para responder a esta pergunta devemos ter em mente um pressuposto epistemológico de natureza histórica: a tese de que somente seria possível compreender o constitucionalismo em perspectiva transnacional, isto é, pós-nacional, a partir da premissa de que se trata de um fenômeno em linha de continuidade histórica com a evolução do constitucionalismo ocidental. Tal pressuposto teórico precisa ser evidenciado porque há uma série de variantes do constitucionalismo que não se enquadram na sua matriz ocidental. ${ }^{40}$

Maurizio Fioravanti costuma definir o constitucionalismo como "um movimento do pensamento voltado, desde suas origens, a perseguir as finalidades políticas concretas, essencialmente consistentes na limitação dos poderes públicos e na afirmação de esferas de autonomia normativamente garantidas." ${ }^{11}$ Já Miguel Maduro sintetiza bem aquelas que são tidas como as três funções essenciais do constitucionalismo: (1) limitar o poder público; (2) expressar os interesses e bens da comunidade política; e (3) integrar a população nos processos deliberativos do Estado.42 Portanto, independentemente da perspectiva adotada, o fenômeno constitucional deve almejar a limitação do poder político e a tutela de direitos fundamentais.

Retornando ao questionamento inicial, qual a relação do combate à desigualdade racial com o constitucionalismo transnacional? Antes de objetivamente responder a essa pergunta, devemos tentar delimitar este conceito. Embora tenha assumido diversas definições (constitucionalismo global ${ }^{43}$, interconstitucionalidade ${ }^{44}$, transcons-

40 Para uma crítica à perspectiva ocidental do constitucionalismo, ver VIOLA, Francesco. South Asian Constitutionalism? A contemporary pathway towards an authentic constitutional order. Revista de Estudos Constitucionais e Hermenêutica do Direito, São Leopoldo, vol. 12, n. 1, p. 78-97, 2020, p. 78-97.

41 FIORAVANTI, Maurizio. Costituzionalismo. Percorsi della storia e tendenze attuali. Roma-Bari: Laterza, 2009, p. 5.

42 Cf. MADURO, Miguel Poaires. A constituição plural: constitucionalismo e União Europeia. Cascais: Principia, 2006, p. 336-337.

43 Em especial, ver FALK, Richard. Human Rights and State Sovereignty. New York: Holmes \& Meier, 1981; FALK, Richard. On Human Governance. Towards a New Global Politics. Cambridge: Polity Press, 1995; FALK, Richard. Predatory Globalization. Cambridge: Polity Press, 1999; para uma crítica, ver TEIXEIRA, Anderson V. Teoria Pluriversalista do Direito Internacional. São Paulo : WMF Martins Fontes, 2011, p. 181-195.

44 Em especial, ver RANGEL, Paulo Castro. Uma teoria da interconstitucionalidade: pluralismo e constituição no pensamento de Francisco Lucas Pires. Revista Themis, [s.l.], ano 1, n. 2, p. 127-151, 2000; e CANOTILHO, Joaquim José Gomes. 'Brancosos' e interconstitucionalidade. Coimbra: Almedina, 2006. 
titucionalismo ${ }^{45}$, apenas para citar algumas variações), em outra oportunidade sustentou-se que o constitucionalismo transnacional pode ser concebido

em termos gerais, como um processo global de afirmação da ubiquidade da existência humana como um bem em si, independentemente de concessões de direitos ou atribuições de sentido/significado estatais, que demanda reconhecimento de direitos não mais vinculados apenas a um Estado nacional específico e que termina redefinindo os objetivos finalísticos do próprio Estado, pois pressiona rumo a integração política internacional e promove, por um lado, diversas esferas transversais de normatividade, enquanto que, por outro, reforça o papel do Estado na proteção interna dos direitos individuais, na afirmação dos direitos culturais e na instrumentalização das políticas globais. ${ }^{46}$

Assim, a resposta ao questionamento inicial fica mais clara e objetiva neste momento: a igualdade racial, enquanto princípio substancial, enquadra-se, por um lado, na perspectiva individual de proteção à subjetividade do indivíduo, enquanto que, por outro lado, insere-se também nas perspectivas sociais e culturais, pois tocam conjuntos de indivíduos não definidos concretamente até que uma lesão em concreto à sua dignidade tenha ocorrido. Portanto, o combate à desigualdade racial é, antes de tudo, uma forma de promoção substancial do princípio da igualdade e de proteção à dignidade humana. Tendo em vista que o constitucionalismo transnacional se desenvolve como um fenômeno de afirmação global da ubiquidade da existência humana, a igualdade racial talvez seja um dos postulados mais ricos de substancialidade e dever-ser para a formulação de políticas públicas globais.

Neste sentido, ganha excepcional relevância a necessidade de desenvolvimento de uma governança global democrática como instrumento de afirmação do constitucionalismo transnacional. Independentemente da perspectiva teórica assumida, já se verifica, de fato, um processo progressivo de transferência para a ordem internacional das prerrogativas que historicamente pertenciam ao Estado-nação. Situações de normalidade mínima permitem que os processos de globalização e cooperação internacional ocorram sem ter à mesa os extremos como opções, isto é, sem o extremo do universalismo utópico que crê em uma república mundial e o desaparecimento gradual dos Estados, sem o extremo dos nacionalismos estatizantes que acreditam cegamente no Estado como a única referência política e normativa.

A pandemia de COVID-19 nos traz importante alerta sobre os perigos que as crises globais podem produzir na tutela dos direitos fundamentais no interior do Estados. Em proveito de um bem que está sob ameaça, relativiza-se a salvaguarda dos demais

45 Em especial, ver NEVES, Marcelo. Transconstitucionalismo. São Paulo: WMF Martins Fontes, 2009.

46 TEIXEIRA, Anderson V. Constitucionalismo transnacional: por uma compreensão pluriversalista do Estado constitucional. Revista de Investigações Constitucionais, Curitiba, vol. 3, n. 3, p. 141-166, 2016, p. 159. 
bens. Em um artigo publicado muito antes da atual crise, Dominique Rousseau advertia que o estado de emergência é um desequilíbrio em favor da ordem pública. ${ }^{47}$ Ademais, o estado de urgência favorece uma atmosfera de segurança e prepara as pessoas para receber as medidas sem se darem conta, sem sentir qualquer ruptura por parte de uma República autoritária e policiesca. ${ }^{48}$

Crises, como a de COVID-19, mostram que, em escala nacional ou internacional, tendem a se replicar as mesmas medidas autoritárias de repressão para fins de normalização em face da excepcionalidade gerada pela crise. No caso do Brasil, até mesmo prefeitos passaram a adotar medidas emergenciais e temporárias de restrição a direitos fundamentais. Mas como fazer se a replicação traz consigo todo um histórico de desigualdades sociais e, especificamente, de opressão racial? Poderia ocorrer a transnacionalização dos mesmos processos que se originaram no interior dos Estados?

Quanto ao Brasil, conforme exposto nos itens anteriores, o problema do racismo estrutural subsiste como um dos grandes desafios ao constitucionalismo democrático, politicamente plural e socialmente multicultural, que conta com a Constituição de 1988 como seu grande ponto de chegada até hoje. No entanto, quando observamos as situações de conflitualidade que já chegaram à jurisdição constitucional, verifica-se que o Supremo Tribunal Federal julgou um caso emblemático em que a discussão de fundo envolvia o fato de que, em não havendo o reconhecimento científico da existência de diferentes raças entre os seres humanos, não poderia haver racismo. Essa era a alegação trazida por um acusado de crime de racismo. No que foi seguido pela maioria dos ministros da Corte, o Min. Maurício Correa reconheceu que, do ponto de vista científico, não haveria mais elementos para a divisão do homem em raças, não procedendo mais a clássica subdivisão da raça humana dotada de características físicas, especialmente no concernente à cor da pele. No entanto, ressaltou o Ministro, a divisão dos hominídeos em raças seria resultado de um processo político-social com base na intolerância. $\mathrm{O}$ antissemitismo seria uma forma de racismo, exatamente por contrapor em sua filosofia duas "raças", uma tida por superior, e outra tida por inferior. ${ }^{49} \mathrm{O}$ mesmo entendimento a respeito da dissociação entre a teoria da raça e o racismo foi adotada no julgamento da ADPF 186, em que, no voto condutor, o Ministro Lewandowski ressaltou que:

cumpre afastar, para os fins dessa discussão, o conceito biológico de raça para enfrentar a discriminação social baseada nesse critério, porquanto se trata de um conceito

\footnotetext{
47 No original: "l'état d'urgence, c'est le déséquilibre au profit de l'ordre public". ROUSSEAU, Dominique. L'état d'urgence, un état vide des droit(s). Revue Projet, [s.l.] vol. 2, n. 291, 2006, p. 19.

48 No original: "favorise un atmosphère sécuritaire et prépare les esprits à recevoir sans s'en apercevoir, sans impression de rupture toute proposition de la République autoritaire et policière". ROUSSEAU, Dominique. L'état d'urgence, un état vide des droit(s). Revue Projet, [s.I.], vol. 2, n. 291, 2006, p. 26.

49 BRASIL. STF. HC 82.424, rel. p/ o ac. min. Maurício Corrêa, voto do min. Gilmar Mendes, j. 17-9-2003, DJ de 19-3-2004.
} 
histórico-cultural, artificialmente construído, para justificar a discriminação ou, até mesmo, a dominação exercida por alguns indivíduos sobre certos grupos sociais, maliciosamente reputados inferiores."150

No âmbito da jurisdição constitucional brasileira, os dois casos citados foram, respectivamente, de controle difuso e de controle concentrado de constitucionalidade. Ambos discutiam questões a priori restritas ao campo das políticas públicas - a ADPF 186 envolvia a políticas de cotas de uma universidade pública. ${ }^{51}$ Quando projetamos o fenômeno constitucional em escala transnacional, somente as declarações de direitos contra desigualdades raciais seriam suficientes para evitar que os mesmos problemas vistos internamente nos Estados não sejam replicados na ordem internacional? 0 tão falado perigo de um constitucionalismo transnacional meramente procedimental, amorfo e voltado tão somente à regulação de aspectos sistêmicos não seria um fértil espaço para a reprodução de distorções já vistas dentro das ordens estatais?

Esses questionamentos nos apontam para três possíveis desafios ao constitucionalismo transnacional.

\section{TRÊS DESAFIOS AO CONSTITUCIONALISMO TRANSNACIONAL NO COMBATE ÀS DESIGUALDADES RACIAIS}

Neste último tópico é fundamental discutir a hipótese de que a possível ausência de um constitucionalismo transnacional definidor, por um lado, de noções substanciais antirracistas e, por outro, de diretrizes de governança global que objetivamente levem em consideração o problema do racismo, poderá produzir efeitos de agravamento do racismo estrutural em países marcados por este fenômeno, como é o caso do Brasil, mas também correrá o risco de replicar em suas próprias estruturas tal fenômeno. Assim, verifica-se que o constitucionalismo transnacional deverá enfrentar três sortes distintas de desafios: teórico-normativo, estrutural-funcional e político-pragmático.

Quanto ao primeiro, situa-se no campo teórico-dogmático precisamente porque o constitucionalismo transnacional é um processo histórico, não revolucionário e vinculado às condições de possibilidade do próprio constitucionalismo ocidental, dentro do qual fora gerado. Seria, portanto, um fenômeno liberal, como na Europa dos séculos XVIII e XIX, ou seria social, como visto nas constituições inspiradas em Weimar? Ou então seria o constitucionalismo transnacional essencialmente vinculado à terceira dimensão dos direitos humanos e restrito à tutela dos direitos dos povos e voltado à solidariedade universal como escopo final? Respostas positivas a tais questionamentos

50 BRASIL. STF. ADPF 186-2, rel. min. Ricardo Lewandowski, j. 26-4-2012, DJ de 20-10-2014.

51 Sobre o julgamento da ADPF 186, ver BRAGATO, Fernanda Frizzo; COLARES, Virginia. Indícios de descolonialidade na Análise Crítica do Discurso na ADPF 186/DF. Revista Direito GV, São Paulo, vol. 13, n. 3, p. 949-980, 2017. 
conduziriam ao reducionismo do fenômeno constitucional transnacional para as condições da temporalidade de cada um dos constitucionalismos que está por trás de cada uma dessas perguntas - ainda que no último questionamento subjaza não o constitucionalismo, mas sim o direito internacional dos direitos humanos.

Ao tentar posicionar no âmbito teórico-dogmático o constitucionalismo transnacional, Marie-Claire Ponthoreau foi não menos precisa do que espirituosa ao dizer que tal fenômeno é "quelque chose" (algo, qualquer coisa) que precisa ser definido, pois está em pleno desenvolvimento e com grande vigor. ${ }^{52}$ Esse "algo" é, antes de tudo, uma construção teórica que empiricamente recolhe elementos formais de constituições nacionais e, recorrendo ao método quantitativo, organiza catálogos de direitos com pretensão de validade universal. ${ }^{53}$ Este é o ponto fundamental, referido por diversos críticos do constitucionalismo transnacional, mas que aqui, por questões metodológicas não faremos uma reconstrução do estado da arte na literatura especializada. Tal ponto é tão fundamental porque esse parece ser o grande desafio que o fenômeno constitucional em perspectiva transnacional precisa enfrentar: adotar uma perspectiva teórico-dogmática que não se limite a "dizer" direitos, de modo meramente formal e sem a devida substancialidade na articulação conceitual. O problema da desigualdade racial é problema que, aparentemente, demandará muito mais do que uma simples dicção formal em proveito da igualdade racial. Em outras palavras, será necessário enfrentar os pormenores, as particularidades, as construções linguísticas que estão em um nível muito mais profundo do que até hoje logrou sucesso em chegar as declarações de direitos baseadas no clássico formulismo do constitucionalismo liberal. Pormenorizar, substancializar, categorizar, são exemplos de verbos que se tornarão necessários para evitar que o constitucionalismo transnacional reste como uma narrativa constitucional distante da realidade da vida dos indivíduos em todos os cantos do mundo.

Quanto ao desafio que chamamos de estrutural-funcional, a ausência de uma centralidade normativa, o caráter histórico do fenômeno e a pluralidade de esferas decisórias apresenta ao constitucionalismo transnacional problemas que prima facie podem parecer insolúveis. Todavia, as experiências de integração, sobretudo na União Europeia, têm demonstrado que temáticas específicas, como a promoção da redução das desigualdades sociais e, em especial, das raciais, possuem locus próprio e especializado, mormente cortes internacionais e comitês de direitos humanos. A emergência de novas crises globais, como a atual de COVID-19, e a urgência que as medidas efetivas podem ganhar futuramente em outras crises demandam um aperfeiçoamento dessas atuais estruturas existentes.

52 PONTHOREAU, Marie-Claire. "Global constitutionalism”, un discours doctrinal homogénéisant. L'apport du comparatisme critique. Jus Politicum. Revue de droit politique, [s.I.], n. 19, p. 105-134, 2018, p. 106.

53 PONTHOREAU, Marie-Claire. "Global constitutionalism”, un discours doctrinal homogénéisant. L'apport du comparatisme critique. Jus Politicum. Revue de droit politique, [s.I.], n. 19, p. 105-134, 2018, p. 121. 
Ainda nos anos 1990, Bruce Ackerman alertava que a emergência de um "constitucionalismo mundial" enfrentaria a dificuldade de não contar com cortes devidamente estruturadas para a solução de suas controvérsias. ${ }^{54}$ Inevitavelmente, a questão constitucional haverá de ser, em algum momento, decidida por um poder que não seja tão somente um poder político, ou seja, deverá ser um poder semelhante a uma corte constitucional. A diversidade de matérias e o grau de substancialidade dos direitos envolvidos têm produzido cortes especializadas no cenário internacional. Portanto, a defesa do princípio da igualdade, em especial da igualdade racial, importará também uma constante reavaliação acerca de qual o melhor e mais eficiente locus decisório para a solução de suas controvérsias.

Quanto ao desafio político-pragmático, talvez seja o de maior complexidade para o constitucionalismo transnacional ao enfrentar a questão do racismo. Há aqui uma necessidade de compreensão das condições políticas e históricas que deram origem ao próprio constitucionalismo ocidental.

O surgimento dos chamados estudos pós-coloniais nos anos 1980 foi de grande valia para discutir o colonialismo não como mero processo de ocupação territorial e consequente controle sobre os meios de produção e sobre as populações que lá habitavam. Tratou-se de uma abordagem teórica que destacou a dimensão do discurso sobre a representação do outro. Edward Said chamava isso de dimensão discursiva do colonialismo, pois não seria mais a ocupação territorial o ponto de referência para o estudo, mas sim o fato de que o colonialismo induziu uma inteira compreensão sobre os modos de ser e de existir mediante a construção de um discurso colonialista. ${ }^{55}$ Diversos autores seguiram nessa perspectiva destacando o caráter representacional do discurso, como Frantz Fanon. ${ }^{56}$

Tomando ambos autores como referências iniciais, Homi Bhabha destaca três características elementares do discurso colonial: a estereotipação, a ambivalência e a mímica. Ele ressalta que "o objetivo do discurso colonial é apresentar o colonizado como uma população de tipos degenerados com base na origem racial de modo a justificar a conquista e estabelecer sistemas de administração e instrução." 57 Nesse sentido, o estereótipo seria uma falsa representação de algo apresentado como realidade. No entanto, não passa de uma simplificação que se mostra presa em uma forma fixa de representação, que, ao negar as diferenças, induz um problema no processo cognitivo de representação do sujeito em significações de relações psíquicas e sociais. Já a

\footnotetext{
54 ACKERMAN, Bruce. The Rise of World Constitutionalism. Virginia Law Review, [s.l.], vol. 83, p. 771-797, 1997, p. 794-796.

55 Ver SAID, Edward. Orientalism. New York: Vintage Books, 1978.

56 Ver FANON, Frantz. The wretched of the earth. New York: Grove Press, 1968; FANON, Frantz. Black skin, white masks. London: Paladin, 1970.

57 BHABHA, Homi. O local da cultura. Belo Horizonte: Editora da UFMG, 1998, p. 111.
} 
ambivalência possibilita a repetibilidade compulsiva de algo que é tomado como fato dado, inequívoco e que dispensaria prova, pois a repetibilidade passa a percepção de ser algo real; as estratégias de individuação e marginalização gerariam um efeito de verdade probabilística que deve sempre estar em excesso em relação que pode ser de fato comprovado empiricamente ou explicado logicamente.

Tendo em vista que o constitucionalismo transnacional origina-se no quadro histórico e teórico do constitucionalismo ocidental, é fundamental enfrentar as dificuldades político-pragmáticas na efetivação de políticas de governança global democrática em proveito da redução das desigualdades raciais. A perspectiva eurocentrista do discurso precisa ter atenção ao fato de que a relação entre colonialidade e a depreciação de certos seres humanos pode resultar em um processo não de redução das desigualdades sociais e raciais, mas, pelo contrário, de ainda maior estereotipização e repetibildiade de um padrão normativo notadamente ocidental.

Portanto, o próprio projeto evolutivo ocidental representado pela modernidade coloca se não a Europa como centro do mundo, mas o Ocidente como tal. O conceito de raça constituiu-se em um instrumento de exercício de poder de matriz colonial, permitindo inferiorizar, mediante o discurso, dominar, mediante o primado de interesses econômicos e políticos. Linda Smith entende que esse processo gerou uma pressuposta superioridade evolutiva da civilização ocidental em virtude de suas formas culturais de viver e conhecer, de suas descobertas científicas e revoluções tecnológicas. ${ }^{58}$

Essa mesma ideia de Ocidente que conformou as nações indígenas por meio do colonialismo precisa ser compreendida dentro de uma perspectiva plural, pluriversalista, abandonando as narrativas universalistas de supremacia moral, histórico-evolutiva, tecnológico-científica do Ocidente, de modo que o constitucionalismo transnacional não seja uma imposição de saberes, línguas e culturas sobre as demais, mas sim uma composição das mais diferentes formas de saber, línguas e culturas. Se o discurso de matriz colonial sustentou-se até hoje com base na colonialidade do saber, impõe-se rever esse padrão de dominação política em proveito de uma diversidade de saberes.

\section{CONCLUSÕES}

Não obstante as dificuldades que a pandemia de COVID-19 possa trazer ao pesquisador, sobretudo quando tomada como um fenômeno ainda em curso, objetivou-se com a presente pesquisa trazer dados parciais relativos ao problema das desigualdades de acesso à saúde por parte de negros e, por consequência, discutir a questão da desigualdade racial no Brasil. Para tanto, a delimitação de fontes de dados foi passo

58 SMITH, Linda Tuhiwai. Decolonizing Methodologies Research and Indigenous Peoples. 12. ed. London: Duneoin, 2008, p. 64. 
fundamental, em especial para evidenciar as imprecisões que a subnotificação de casos gera para que se obtenha uma imagem definitiva desse fenômeno ainda em curso.

Porém, os dados quantitativos serviram apenas para suscitar uma discussão de fundo muito mais profunda: o racismo em suas vertentes institucional e estrutural. Tratando-se de problema endêmico no tecido social brasileiro, discutiu-se o modo como o emergente cenário de governança global em temas sensíveis, como a saúde, poderá gerar possíveis dificuldades, por um lado, ao Brasil, caso não apresente melhores resultados no combate ao racismo estrutural, enquanto que, por outro lado e de modo muito mais gravoso, ao constitucionalismo transnacional em face do sério perigo de que patologias sociais, como o racismo, sejam potencializadas em dimensão global.

Nesse sentido, a pesquisa buscou introduzir uma hipótese teórica que, com base em uma matriz que combina elementos pós-estruturalistas, descoloniais e pluriversalistas, apresenta possíveis encaminhamentos para a superação dos três desafios anteriormente suscitados. Os cenários posteriores a grandes crises apontam, historicamente, para revoluções ou reformas estruturais. Talvez seja o cenário pós-pandemia a oportunidade para reformas estruturais tanto no âmbito interno dos países quanto na ordem transnacional.

\section{REFERÊNCIAS}

ACKERMAN, Bruce. The Rise of World Constitutionalism. Virginia Law Review, [s.l.], vol. 83, p. 771797, 1997.

ALMEIDA, Silvio. Racismo estrutural. São Paulo: Pólen, 2019.

BETHENCOURT, Francisco. Racismo: das Cruzadas ao século XX. São Paulo: Companhia das Letras, 2018.

BHABHA, Homi. O local da cultura. Belo Horizonte: Editora da UFMG, 1998.

BRAGATO, Fernanda Frizzo; COLARES, Virginia. Indícios de descolonialidade na Análise Crítica do Discurso na ADPF 186/DF. Revista Direito GV, São Paulo, vol. 13, n. 3, p. 949-980, 2017.

CANOTILHO, Joaquim José Gomes. 'Brancosos' e interconstitucionalidade. Coimbra: Almedina, 2006.

CIDH. COMISSÃO INTERAMERICANA DE DIREITOS HUMANOS. Relatório n. 66/06. Caso 12.001 MÉRITO. SIMONE ANDRÉ DINIZ BRASIL, 21 de outubro de 2006.

FALK, Richard. Human Rights and State Sovereignty. New York: Holmes \& Meier, 1981.

FALK, Richard. On Human Governance. Towards a New Global Politics. Cambridge: Polity Press, 1995.

FALK, Richard. Predatory Globalization. Cambridge: Polity Press, 1999. 
FANON, Frantz. The wretched of the earth. New York: Grove Press, 1968.

FANON, Frantz. Black skin, white masks. London: Paladin, 1970.

FIORAVANTI, Maurizio. Costituzionalismo. Percorsi della storia e tendenze attuali. Roma-Bari: Laterza, 2009.

FOUCAULT, Michel. L'archéologie du savoir. Paris: Gallimard, 1969.

FOUCAULT, Michel. Microfísica do poder. 4 ed. Rio de Janeiro: Graal, 1984.

JAKOBSON, Roman. Essais de linguistique générale. Tomos I e II. Paris: Les Éditions de Minuit, 1963; 1973.

JONES, Camara P. Confronting Institutionalized Racism. Phylon, [s.I.], vol. 50, n. 1/2, p. 7-22, 2002.

KALCKMANN, Suzana; SANTOS, Claudete Gomes dos; BATISTA, Luís Eduardo; CRUZ, Vanessa Martins da. Racismo institucional: desafio para a equidade no SUS? Saúde e Sociedade, [s.I.], vol. 16, n. 2, p. 146-155, 2007.

LÉVI-STRAUSS, Claude. Anthropologie structurale. Paris: Plon, 1958.

LÉVI-STRAUSS, Claude. Tristes tropiques. Paris: Plon, 1958.

LÉVI-STRAUSS, Claude. Race et Histoire; Race et Culture. Paris: Albin Michel et UNESCO, 2001.

MADURO, Miguel Poiares. A constituição plural: constitucionalismo e União Europeia. Cascais: Principia, 2006.

NEVES, Marcelo. Transconstitucionalismo. São Paulo: WMF Martins Fontes, 2009.

PETERS, Michael. Pós-estruturalismo e filosofia da diferença. Belo Horizonte: Autêntica, 2000.

PIAGET, Jean de. Le structuralisme. Paris: PUF, 1968.

PIRES, Luiza Nassif; XAVIER, Laura de Lima; CARVALHO, Laura. Coronavírus e desigualdade no Brasil. CEBES, 06 de abril de 2020. http://cebes.org.br/2020/04/covid-19-e-desigualdade-no-brasil/

PONTHOREAU, Marie-Claire. "Global constitutionalism", un discours doctrinal homogénéisant. L'apport du comparatisme critique. Jus Politicum. Revue de droit politique, [s.l.], n. 19, p. 105134, 2018.

RANGEL, Paulo Castro. Uma teoria da interconstitucionalidade: pluralismo e constituição no pensamento de Francisco Lucas Pires. Revista Themis, [s.I.], ano 1, n. 2, p. 127-151, 2000.

ROUSSEAU, Dominique. L' état d'urgence, un état vide des droit(s). Revue Projet, [s.I.], vol. 2, n. 291, p.19-26, 2006.

SAID, Edward. Orientalism. New York: Vintage Books, 1978.

SMITH, Linda Tuhiwai. Decolonizing Methodologies Research and Indigenous Peoples. 12. ed. London: Duneoin, 2008. 
TEIXEIRA, Anderson V. Constitucionalismo transnacional: por uma compreensão pluriversalista do Estado constitucional. Revista de Investigações Constitucionais, Curitiba, vol. 3, n. 3, p. 141-166, 2016.

TEIXEIRA, Anderson V. Teoria Pluriversalista do Direito Internacional. São Paulo : WMF Martins Fontes, 2011.

TORODOV, Tzvetan. Nosotros y los otros: reflexión sobre la diversidad humana. Madrid: Siglo $\mathrm{XXI}, 2007$.

VIOLA, Francesco. South Asian Constitutionalism? A contemporary pathway towards an authentic constitutional order. Revista de Estudos Constitucionais e Hermenêutica do Direito, São Leopoldo, vol. 12, n. 1, p. 78-97, 2020.

WAYNE, C. K.; WILLIAMS, Michelle. Covid-19 and Immunity in Aging Populations - A New Research Agenda. The New England Journal of Medicine, [s.l.], vol. 383, n. 9, p. 804-805, abr. 2020.

WERNECK, Jurema. Racismo institucional e saúde da população negra. Saúde e Sociedade, [s.I.], vol. 25, n. 3, p. 535-549, 2016. 